\title{
Carga parasitária x estresse oxidativo em Satanoperca jurupari (Heckel, 1840) na Amazônia Oriental
}

Objetivou-se nesse trabalho verificar a carga parasitária da espécie Satanoperca jurupari (Heckel, 1840) e sua relação com a resposta bioquímica por meio da determinação dos teores de tióis totais (GSH) e dos produtos finais da lipoperoxidação, aspectos até então não estudados para a espécie e região. As coletas foram realizadas de outubro de 2017 a outubro de 2018 , no rio Curiaú, zona rural da capital do Estado do Amapá. A análise de estresse oxidativo foi determinado após a homogenização do fígado de peixes da espécie Satanoperca jurupari, para determinar os produtos finais da peroxidação lipídicas (SRAT) e GSH. Para análise parasitológica, utilizou-se as técnicas de microscopia de luz (DIC e Histologia). Nos resultados obtidos do presente trabalho, há correlação negativa $(-0,474)$ entre os teores de glutationa reduzida e SRAT, evidenciado níveis de estresse oxidativo moderados, com consumo de GSH e elevação dos presente trabalho, há correlação negativa (-0,474) entre os teores de glutationa reduzida e SRAT, evidenciado niveis de estresse oxidativo moderados, com consumo de GSH e elevação do de danos nos lipídeos de membrana causados pela infecção por parasitos. Foram identificados 3 gêneros do subfilo Myxoza: na vesícula biliar, Ceratomyxa e Ellipsomyxa, nas brânquias, Henneguya. Nas nadadeiras, tegumento, boca, brânquias, opérculo e olhos foi encontrado 1 representante do filo Microsporidia. Registrou-se pela primeira vez a ocorrência de microparasitas dos gêneros Ellipsomyxa e Ceratomyxa, e a segunda de Henneguya, assim como o primeiro registro de ocorrência de microsporídio para esta espécie. Com base em uma abordagem biológica integrada inferindo que a função de defesa antioxidante (GSH) e a oxidação dos lipídicos (SRAT) foram impactadas pela taxa de infecção, de forma sistêmica, sugerindo que funções hepáticas são alteradas. Estes resultados revelam a necessidade de maiores estudos referentes às características biológicas como detalhamento em microscopia eletrônica e biologia molecular para identificação e descrição a nível de espécie. O presente estudo forneceu também informações valiosas sobre efeitos de parasitas em uma espécie amazônica e sublinhou a importância da avaliação da associação dos marcadores de estresse oxidativo e a carga parasitária.

Palavras-chave: Estresse Oxidativo; Myxozoa; Microsporidia; Peixe.

\section{Parasitary load x oxidative stress in Satanoperca jurupari (Heckel, 1840) in the Eastern Amazon}

\begin{abstract}
The objective of this work was to verify the parasitic load of the species Satanoperca jurupari (Heckel, 1840) and its relationship with the biochemical response by determining the levels of to Curiaú River, rural area of the capital of the state of amapá. The analysis of oxidative stress was determined after liver's homogenization of fish of the species Satanoperca jurupari, to Curiaú River, rural area of the capital of the state of amapa. The analysis of oxidative stress was determined after liver's homogenization of fish of the species Satanoperca jurupari, to
determine the final products of lipid peroxidation (SRAT), GSH and for parasitological analysis, light microscopy techniques (DIC and Histology) were used. In the results obtained from the determine the final products of lipid peroxidation (SRAT), GSH and for parasitological analysis, light microscopy techniques (DIC and Histology) were used. In the results obtained from the
present study, there is a negative correlation $(-0.474)$ between the levels of reduced glutathione and SRAT, evidencing levels of moderate oxidative stress, with consumption of GSH and elevation of the levels of SRAT, however there is no exacerbated occurrence of oxidative damage to biomolecules. Due to the parasitar load, the consumption of GSH is evident and the moderate generation of damage to membrane lipids caused by infection by parasites. Three genera of the subphylum Myxozoa were identified: in the gallbladder, Ceratomyxa and Ellipsomyxa, in the gills, Henneguya. In the fins, integument, mouth, gills, operculum and eyes, 1 representative of the phylum Microsporidia was found. The first occurrence of microparasites of the genera Ellipsomyxa and Ceratomyxa was recorded, and the second of Henneguya, for this cichlid, as well as the first occurrence of microsporidium for this species in the state of Amapá. Based on an integred that liver funtions are altere. These results real the need for fun ( (d) importance of assessing the association of oxidative stress markers and parasitic load.
\end{abstract}

Keywords: Oxidative stress; Myxozoa; Microsporidia; Fish

Roger Leomar da Silva Ferreira (iD) Universidade do Estado do Amapá, Brasil http://lattes.cnpq.br/3436682345893190 http://orcid.org/0000-0001-5316-0380 rogersilfer@yahoo.com.br

\section{Angley Pantoja Pinheiro in}

Universidade do Estado do Amapá, Brasil http://lattes.cnpq.br/3842869738628189 http://orcid.org/0000-0002-0104-0632 angleyim@gmail.com

Arllon José dos Santos Dias (iD

Universidade do Estado do Amapá, Brasil http://lattes.cnpq.br/1158053855228481 http://orcid.org/0000-0003-3812-9013 arllon0006@gmail.com

\author{
Abthyllane Amaral de Carvalho (iD) \\ Universidade Federal do Pará, Brasil \\ http://lattes.cnpq.br/1247132992493228 \\ http://orcid.org/0000-0001-9598-1590 \\ abthyllaneamaral@gmail.com \\ Edilson Rodrigues Matos \\ Universidade Federal Rural da Amazônia, Brasil \\ http://lattes.cnpq.br/7895814591867510 \\ http://orcid.org/0000-0002-9918-1408 \\ edilson.matos9@gmail.com

\section{Gabriel Araújo da Silva} \\ Universidade do Estado do Amapá, Brasil \\ http://lattes.cnpq.br/8633733418545174 \\ http://orcid.org/0000-0002-9073-1995 \\ gabriel.silva@ueap.edu.br
}

\author{
Marcela Nunes Videira \\ Universidade do Estado do Amapá, Brasil \\ http://lattes.cnpq.br/0155583853689152 \\ http://orcid.org/0000-0002-9559-8521 \\ videiravet@gmail.com
}

\section{Referencing this:}

FERREIRA, R. L. S.; PINHEIRO, A. P.; DIAS, A. J. S.; CARVALHO, A. A.; MATOS, E. R.; SILVA, G. A.; VIDEIRA, M. N.. Carga parasitária x estresse oxidativo em Satanoperca jurupari (Heckel, 1840) na Amazônia Oriental. Revista Ibero Americana de Ciências Ambientais, v.12, n.3, p.136-144, 2021. DOI: http://doi.org/10.6008/CBPC21796858.2021.003.0013 


\section{INTRODUÇÃO}

Os peixes podem ser hospedeiros de uma grande diversidade de organismos que estão distribuídos dentro de diversos grupos, podendo ter o seu desenvolvimento afetado tanto em ambientes naturais como em ambientes de cultivo (EIRAS et al., 2010). O Satanoperca jurupari Heckel, 1840, é um peixe popularmente conhecido como acará-bicudo, que possui ampla distribuição na América do Sul (KULLANDER, 2003). Este ciclídeo ornamental é onívoro e se alimenta de microcrustáceos, sementes de frutas, gramíneas e peixes pequenos, bem como larvas de insetos aquáticos e terrestres (TAVARES-DIAS et al., 2017).

Os parasitos causadores de enfermidades em peixes são abundantes e apresentam membros dos diferentes grupos zoológicos (FLORINDO et al., 2016). Os hospedeiros e parasitos são envolvidos em uma relação de disputa por recursos imunológicos e bioquímicos. Enquanto que restrições podem definir um limite para o possível resultado dessas interações, fica claro que estamos longe de quadro completo das estratégias de proteção imunológica e fuga imune (SORCl et al., 2009).

A descoberta recente que patógenos podem induzir uma resposta antioxidante diretamente relacionada ao grau de infecção, ou seja, em baixo grau de infecção apresentar aumento moderado das defesas antioxidantes do hospedeiro suficiente para impedir danos celulares naturalmente gerados, enquanto que quando altamente infectado levam à produção excessiva de espécies reativas de oxigênio ou nitrogênio (ERO e ERN) que podem comprometer a sobrevivência do organismo, processos estes que ainda estão sendo elucidados (KHO et al., 2018; BOX et al., 2020).

Todavia, é sabido que as interações parasito-hospedeiro podem gerar estresse oxidativo, que é definido como um desequilíbrio entre os sistemas oxidantes e antioxidantes em favor dos primeiros. São geradas inúmeras espécies reativas, levando a ocorrência dos danos oxidativos nas biomoléculas, em especial aos lipídios de membrana, pelo processo de lipoperoxidação (JOARDAR et al., 2020).

Para monitorar o status oxidativo de um organismo se faz uso de biomarcadores bioquímicos, como glutationa reduzida (GSH) e os produtos finais da lipoperoxidação, que são extremamente sensíveis a qualquer alteração fisiológica do hospedeiro, quando exposto aos xenobióticos ou patógenos. Esses biomarcadores quando aplicados em programas de monitoramento oferecem algumas vantagens porque são normalmente os primeiros a serem detectados, apresentam alta especificidade, possuem baixo custo de análise e fornecem informações a respeito do efeito metabólico causado pelo xenobiótico ou parasito (RAHAL et al., 2014).

Desta forma, o presente trabalho objetivou verificar a carga parasitária do peixe amazônico Satanoperca jurupari Heckel,1840 e sua relação com a resposta bioquímica por meio da determinação dos teores de GSH e dos produtos finais da lipoperoxidação, aspectos até então não estudados para a espécie e região. 


\section{MATERIAIS E MÉTODOS}

\section{Coleta e transporte do material biológico}

Os espécimes de peixes utilizados nesse estudo foram provenientes do rio Curiaú, Macapá-AP, no entorno correspondente ao ponto $\left(0^{\circ} 8^{\prime} 43.6^{\prime \prime} \mathrm{N}, 51^{\circ} 2^{\prime} 30.3^{\prime \prime} \mathrm{W}\right)$ (Fig. 1), sendo capturados pela equipe do Laboratório de Morfosiologia e Sanidade Animal (LABMORSA/UEAP) auxiliados por pescadores locais com a utilização de tarrafa de 30mm entre nós.

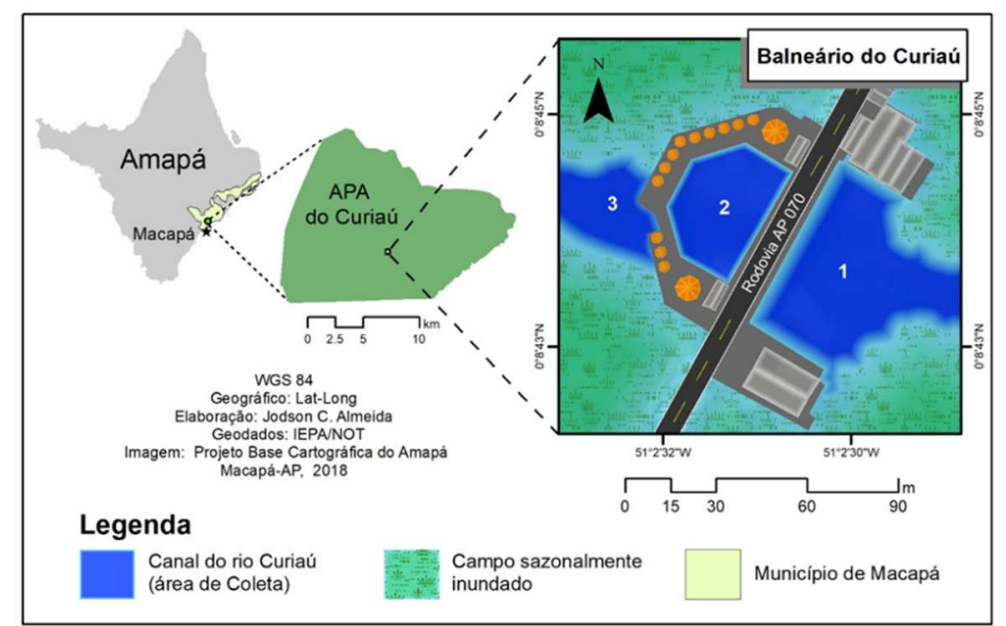

Figura 1: Mapa do estado do Amapá com destaque na Área de Proteção Ambiental do Rio Curiaú (Norte), na imagem maior vemos o local de estudo com os 3 pontos de coleta (1, 2 e 3).

Foram realizadas 7 coletas de outubro de 2017 a outubro de 2018, totalizando 31 indivíduos, devido ao tamanho dos peixes e massa dos fígados, 06 espécimes foram utilizados para determinação dos biomarcadores. As coletas foram autorizadas pelo Comitê de Uso Animal da Empresa Brasileira de Pesquisa Agropecuária - Amapá (EMBRAPA/SEI 012) e com cadastro no Sistema de Autorização e Informação em Biodiversidade (SISBIO/ICMBIO Licença 50376-1).

Os animais foram acondicionados vivos em caixas térmicas e transportados vivos com auxílio de bombas à pilha até o LABMORSA/UEAP, onde procederam às análises parasitológicas e após a retirada e pesagem dos fígados, foram levados ao Laboratório de Química Orgânica e Bioquímica (UEAP).

Os animais foram anestesiados com água fria e gelo e posteriormente eutanasiados através de secção medular. Em seguida foi feita a biometria: pesados $(\mathrm{g})$ e medidos $(\mathrm{cm})$. Sendo analisada toda a superfície corpórea através de microscópio estereoscópico binocular, para verificar a existência de lesões (cistos) ou perda de revestimento (escamas e epiderme). Em seguida realizou-se incisões, na região ventral, a fim de expor suas vísceras para que cada órgão pudesse ser examinado minuciosamente, seu fígado retirado e pesado.

\section{Técnicas de microscopia}

Dos tecidos onde foram encontrados possíveis focos de desenvolvimento de parasitos, retiram-se pequenos fragmentos, coletados com pinças e colocados entre lâmina e lamínula, para serem observados através de microscopia de luz (ML) e em Contraste de Interferência Diferencial DIC (ZEISS - Axio Cam ERC 5S). 
Nos casos afirmativos para o parasitismo, os tecidos foram fixados em Davidson (álcool 95\%, formaldeído e ácido acético, água destilada) e processados pelas técnicas habituais de histologia para inclusão em parafina, corados com hematoxilina e eosina (H\&E) (LUNA, 1968).

\section{Análises parasitológicas}

A metodologia para a coleta e processamento de parasitos foi de acordo com a descrita por Eiras et al. (2010), para cálculo de prevalência a metodologia adotada foi a de Bush (1997). A carga parasitária total foi calculada considerando uma escala de pontuações, diferenciados em órgãos com contaminação leve (1 ponto), média ( 2 pontos) ou alta (3 pontos). Ao final todos os sítios foram somados (MEHLHORN, 2016).

\section{Análises dos biomarcadores}

\section{Preparo do homogenato de fígado}

Para a quantificação dos marcadores foram utilizadas amostras de fígado do S. jurupari

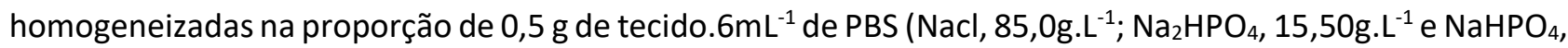
2,30g. $\mathrm{L}^{-1}$ ) com pH 7,2 ajustado com $\mathrm{NaOH}(1 \%)$. O homogeneizado no Graal e pistilo, sendo adicionado mais $4 \mathrm{~mL}$ de PBS que foi centrifugado a $3500 \mathrm{rpm} .10 \mathrm{~min}^{-1}$. Uma alíquota do sobrenadante de foi separado para a determinação de proteínas totais pelo método de Lowry et al. (1951), sendo os resultados expressos em $\mu \mathrm{g} \cdot \mathrm{mL}^{-1}$.

\section{Determinação dos produtos finais da peroxidação lipídica (SRAT)}

Os produtos finais da peroxidação lipídica (peróxidos lipídicos, malondialdeídos e demais aldeídos de baixo peso molecular), ao reagirem com o ácido 2-tiobarbitúrico (TBA) e ácido tricloracético (TCA), formam Bases de Schiff. Tais complexos são coloridos e sua concentração foram determinadas espectrofotometricamente a $535 \mathrm{~nm}$ (YEANG et al., 1998).

Em tubos de ensaio, foram pipetados $100 \mu \mathrm{L}$ sobrenadante do homogenato, branco ou padrão. A cada tubo de ensaio foi adicionado $1 \mathrm{~mL}$ de reagente TBA $0,73 \% /$ TCA $15 \%$. As amostras foram submetidas a aquecimento em banho-maria, sob temperatura controlada (100ㄷ), durante 30 minutos e, em seguida, submetidas ao resfriamento, em banho de gelo, por 10 minutos e, após centrifugadas à $3500 \mathrm{rpm} \cdot \mathrm{min}^{-1}$. A leitura foi realizada em espectrofotômetro a $535 \mathrm{~nm}$, em triplicata com valores expressos em mM/g.

\section{Determinação dos teores de tiois totais (em equivalentes de GSH)}

A glutationa, principal tiol intracelular, reage com o ácido 5,5'-ditio-bis-2- nitrobenzóico (DTNB), formando um tiolato (TNB ou ácido 5-tio-2-nitrobenzóico) de coloração amarelada, mensurável espectrofotometricamente a $420 \mathrm{~nm}$.

A adição de $500 \mu \mathrm{L}$ de DTNB (1 mg/mL de citrato de sódio $1 \%$ ) nas cubetas contendo $500 \mu \mathrm{L}$ da amostra diluída em 1,5 mL de tampão fosfato $\mathrm{pH} 8(0,2 \mathrm{M})$ permitiu a quantificação de tióis totais expressos 
em equivalentes de glutationa reduzida (GSH), após banho-maria, sob temperatura controlada $\left(37^{\circ} \mathrm{C}\right)$, durante 3 minutos e, em seguida, submetidas ao resfriamento em banho de gelo, a absorbância foi determinada a $420 \mathrm{~nm}$. As análises foram feitas em triplicatas e os valores expressos em $\mathrm{mM} / \mathrm{g}$ de tecido.

\section{Análises dos dados}

Os dados foram analisados no software Microsoft Excel ${ }^{\circledR}$ para Windows, versão 2010. Os dados foram expressos como a média \pm erro padrão $(n \geq 5)$. Diferenças significativas nos dados foram analisadas pela correlação de pearson $(\mathrm{P} \leq 0,05)$ usando o programa $R$.

\section{RESULTADOS E DISCUSSÃO}

O Satanoperca jurupari é uma espécie de ciclídeo com ampla distribuição (Fig. 2) no sistema do rio Amazonas, no Brasil, Colômbia, Equador, Guianas, Peru, Suriname, Venezuela e Bolívia (KULLANDER, 2003; FROESE et al., 2016; TAVARES-DIAS et al., 2017; FERREIRA et al., 2020).

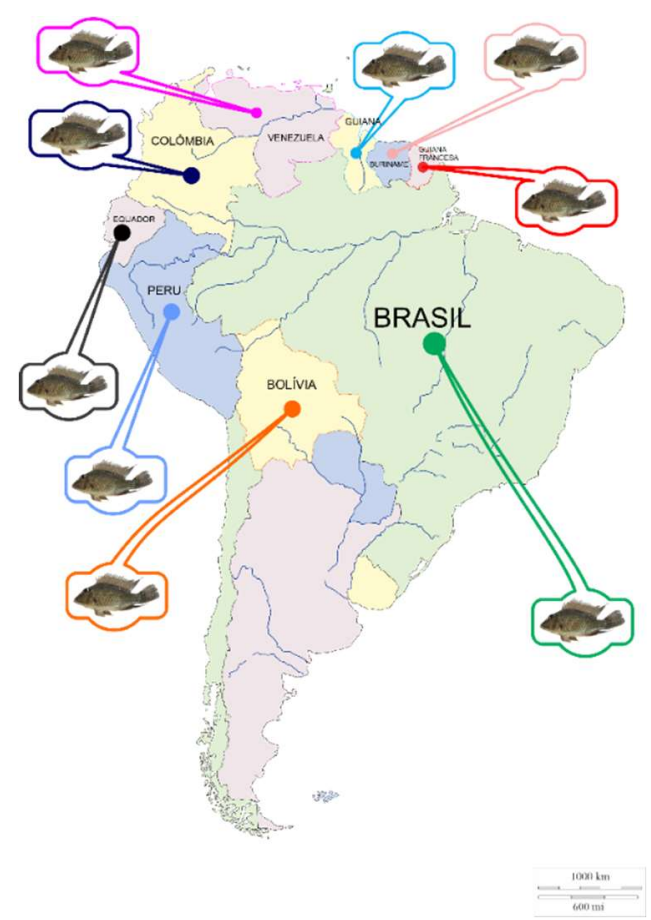

Figura 2: Mapa de distribuição.

Os espécimes de $S$. jurupari coletados tiveram o comprimento médio de $15,35 \pm 1,38 \mathrm{~cm}$ e um peso médio de 56,09 $\pm 10,36 \mathrm{~g}$. Dos 31 espécimes coletados de ciclideos nativos, S. jurupari, 100\% estavam infectados por microparasitos e demonstraram susceptibilidade parasitológica a uma variedade de espécies de parasitos, tornando-se preocupante, pois além do interesse para aquarismo, é consumido pela comunidade quilombola que ali habita e também pode ser utilizado na aquicultura como espécie forrageira.

Eiras et al. (2010) afirma que peixes de água doce podem abrigar uma grande variedade de espécies de parasitos, sejam esses ectoparasitos ou endoparasitos, pertencentes a numerosos filos. Essa espécie de peixe obtém alimento fuçando sedimentos, enterrando o focinho na terra, uma das justificativas para que sua fauna microparasitária seja elevada. 
Nesse estudo foram verificados 2 filos de interesse: Microsporidia Balbiani, 1882 e Myxozoa Grasse, 1970, (Fig. 3) como pode ser visto na tabela 1, a prevalência dos filos encontrados. Ferreira et al. (2020) descreveram uma espécie do Gênero Henneguya Thélohan, 1892, Henneguya sacacaensis para esse hospedeiro, que causa uma leve hiperplasia entre os filamentos branquiais.

Tabela 1: Prevalência microparasitária e sítio de infecção nos órgãos de S. jurupari da área de Proteção Ambiental do rio Curiaú-AP.

\begin{tabular}{lll}
\hline Microparasitos & Prevalência & Sítio de infecção \\
\hline Microsporídio & $36,36 \%$ & Nadadeiras, tegumento, boca, brânquias, opérculo e olhos \\
Ceratomyxa sp. & $27,27 \%$ & Vesícula biliar \\
Ellipsomyxa sp. & $45,45 \%$ & Vesícula biliar \\
Henneguya sp. & $72,73 \%$ & Brânquias \\
\hline
\end{tabular}
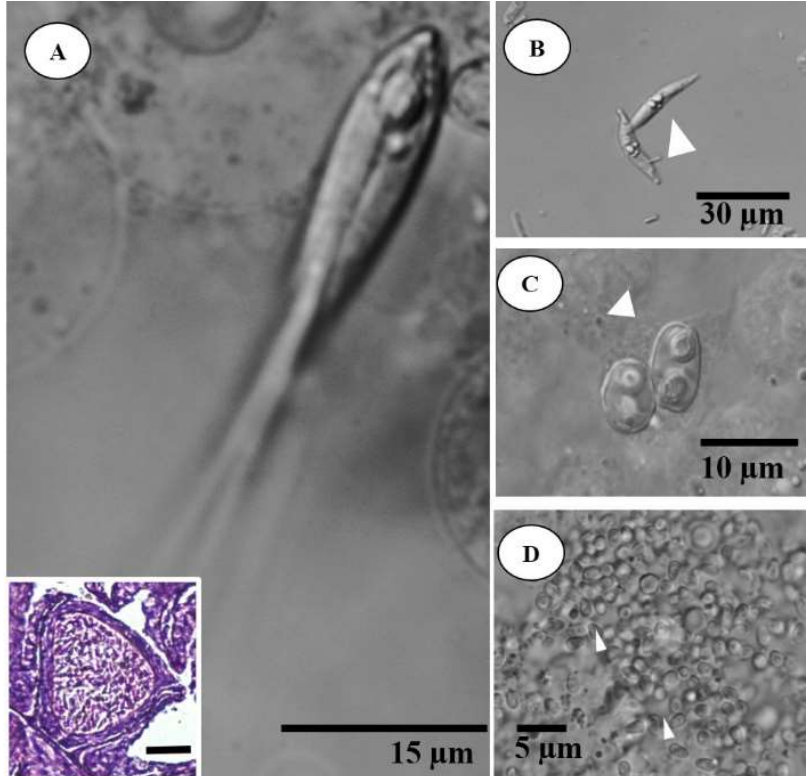

$15 \mu \mathrm{m}$

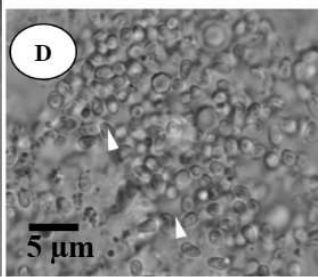

Figura 3: Fotomicrografia dos Gêneros encontrados no Hospedeiro em estudo. A. Henneguya Inset: Corte histológico de um cisto no filamento branquial corado em Hematoxilina e Eosina. Barra de escala $5 \mu \mathrm{m}$. B) Esporos de Ceratomyxa sp. C) Esporos de Ellipsomyxa sp. D) Esporos de microsporidios.

Assim, para avaliar as relações parasito-hospedeiro e o status oxidativo dos animais foi selecionado como órgão para análise o fígado, pois não apresentou infecção direta por parasitos na grande maioria dos animais avaliados e é o órgão metabolizador, responsável pela detoxificação, bem como a produção excessiva de ERO e ERN, gerada a partir de várias enzimas bioquímicas oxidativas endógenas, que interfere na função normal das células específicas e, presumivelmente, desempenha um papel na patogênese das diversas desordens hepática, inclusive as relacionadas com a infecção por parasitos (LUANGMONKONG et al., 2018). No presente trabalho, as relações entre os teores de glutationa reduzida e produtos finais da lipoperoxidação foram relacionados a carga parasitaria total dos indivíduos, como apresentado na tabela 2.

Tabela 2: Correlação de Pearson entre os biomarcadores de estresse oxidativo e a carga parasitária de $S$. jurupari da área de Proteção Ambiental do rio Curiaú-AP.

\begin{tabular}{llll}
\hline & Carga parasitária & GSH $\left(\mathbf{m M} \cdot \mathbf{g}^{-1}\right)$ & SRAT $\left(\mathbf{m M} \cdot \mathbf{g}^{-1}\right)$ \\
\hline Carga parasitária & 1 & $-0,762$ & 0,248 \\
GSH $\left(\mathrm{Mm}^{-1}\right)$ & & 1 & $-0,474$ \\
SRAT $\left(\mathrm{mM} \cdot \mathrm{g}^{-1}\right)$ & & & 1 \\
\hline
\end{tabular}

GSH, tióis totais em equivalentes de glutationa reduzida; SRAT, substâncias reativas ao ácido tiobarbitúrico; mM.g ${ }^{-1}$, milimolar por grama de tecido. 
A glutationa reduzida é um tripepitídeo rico em terminações sulfidrilas (-SH) que o caracterizam como o antioxidante intracelular mais abundante, assim o sistema de defesa antioxidante que utiliza os tióis como fonte redutora são os primeiros sistemas a serem consumidos pelas ERO ou ERN gerados. Nos resultados obtidos do presente trabalho, há correlação negativa $(-0,474)$ entre os teores de glutationa reduzida e SRAT, evidenciado níveis de estresse oxidativo moderado, com consumo de tióis totais e elevação dos teores de SRAT, porém não há ocorrência exacerbada de danos oxidativos as biomoléculas, principalmente lipídeos de membrana (GUTTERIDGE et al., 2018; FARZAEl et al., 2018; MEDA et al., 2019).

Ao analisar de forma isolada os biomarcadores utilizados no presente estudo com a carga parasitária é evidente o consumo de tióis de forma acentuada e a geração moderada de danos nos lipídeos de membrana causados pela infecção por parasitos, como mostrado na figura 3.

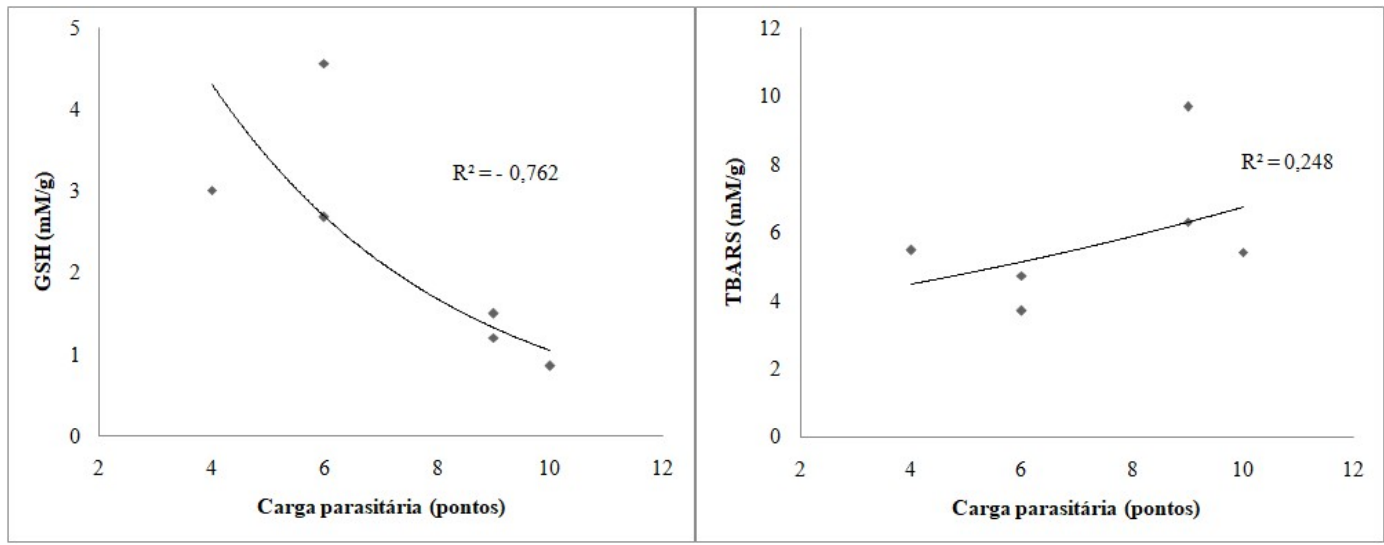

Figura 3: Gráficos de correlação entre os teores de tióis totais (GSH), produtos finais da lipoperoxidação (SRAT) e carga parasitária de Satanoperca jurupari da área de Proteção Ambiental do rio Curiaú-AP.

É notório que os processos inflamatórios estão associados as infecções por parasitos e levam a formação de ERO e ERN por processos bioquímicos diversos, tanto pela defesa imunulógica especializada quanto pela indução de processos inflamatórios inespecíficos (SORCl et al., 2009). Essas espécies reativas formadas consomem o sistema de defesa antioxidante não enzimático (ácido ascórbico e betacaroteno), que é restaurado com o consumo dos tióis totais presentes no meio intracelular, principalmente a glutationa reduzida, por isso foi evidente a relação negativa $(-0,762)$ entre a abrangência das infecções parasitárias com níveis baixos de GSH, ou seja, quanto maior for a ocorrência de parasitos, menor será os níveis de GSH (JOARDAR et al., 2020; TURRENS, 2004).

Apenas ocorrem danos oxidativos generalizados nas membranas plasmáticas após a depleção dos sistemas de defesa antioxidante não-enzimático e enzimático intrínsecos as células e o desequilíbrio entre a produção de espécies reativas e os sistemas de defesa, ou seja, instauração do estresse oxidativo, com a formação exacerbada de produtos finais da lipoperoxidação, tais como o malonildialdeído (MDA), no presente trabalho quantificados como SRAT. Assim, níveis elevados de SRAT são característicos de organismos em situação de estresse oxidativo (GASCHLER et al., 2017). No estudo, foi mostrado que houve o aumento moderado dos teores de SRAT com o aumento da carga parasitária, assim demonstrando uma correlação positiva $(0,248)$. Em outros estudos similares, também foram observadas correlações entre os níveis dos marcadores de lipoperoxidação e grau de infecção parasitária (BOX et al., 2020; NABI et al., 2017; 
LACAZE et al., 2019). Todavia, estudos de correlação dos impactos das infecções parasitárias na geração de estresse oxidativo são recentes e as referências ainda são limitadas, a maioria dos relatos em peixes é com foco em aspectos ecológicos, pesticidas ou compostos inorgânicos (PAITAL et al., 2019; SRIVASTAVA et al., 2017; KAPTANER et al., 2019).

\section{CONCLUSÕES}

O conhecimento da fauna parasitária dos peixes possibilita um diagnóstico e um controle sanitário adequado a cada região pesquisada, podendo evitar causas de surtos de doenças desconhecidas, possivelmente subdiagnosticadas, por consumo impróprio do pescado em determinadas regiões que sofrem influência antrópica, como no caso da comunidade nas proximidades do rio Curiaú-AP.

O Satanoperca jurupari apresentou uma variedade na fauna microparasitária, com destaque ao filo Myxozoa. Registrou-se pela primeira vez a ocorrência de microparasitas dos gêneros Ellipsomyxa e Ceratomyxa, e a segunda do Henneguya, para este ciclídeo, assim como o primeiro registro de ocorrência de microsporídio para esta espécie no estado do Amapá. Estes resultados preliminares revelam a necessidade de maiores estudos referentes às características biológicas como detalhamento em microscopia eletrônica e biologia molecular para identificação e descrição a nível de espécie.

Um desafio particular ao estudo de campo é avaliar as interações de múltiplos impactos ambientais, como impactos naturais e antropogênicos estressores. Este estudo investigou os impactos cumulativos de parasitas na saúde de peixes da espécie $S$. jurupari, com base em uma abordagem biológica integrada inferindo que a função de defesa antioxidante (GSH) e a oxidação dos lipídicos (SRAT) foram impactadas pela taxa de infecção, de forma sistêmica, sugerindo que funções hepáticas são alteradas. O presente estudo forneceu informações valiosas sobre efeitos de parasitas em uma espécie amazônica e sublinhou a importância de incluir a avaliação ambiental da carga parasitária.

\section{REFERÊNCIAS}

BOX, A.; CAPÓ, X.; TEJADA, A. S.; MEJIAS, L.; VALENCIA, J. S.. Perkinsus mediterraneus infection induces oxidative stress in the mollusc Mimachlamys varia. Journal of Fish Diseases, v.43, n.1, p.1-7, 2020. DOI: http://doi.org/10.1111/ifd.13085

BUSH, A. O.; LAFFERTY, K. D.; LOTZ, J. M.; SHOSTAK, W.. Parasitology meets ecology on its own terms: Margoliset al. The Journal of Parasitology, v.83, n.4, p.575-583, 1997. DOI: http://doi.org/10.2307/3284227

EIRAS, J. C.; TAKEMOTO, R. M.; PAVANELLI, G. C.. Métodos de estudo e técnicas laboratoriais em parasitologia de peixes. 2 ed. EDUEM, 2010.

FARZAEI, M. H.; ZOBEIRI, M.; PARVIZI, F.; EL-SENDUNY, F. F.; MARMOUZI, I.; COY-BARRERA, E.; ABDOLLAHI, M.. Curcumin in liver diseases: a systematic review of the cellular mechanisms of oxidative stress and clinical perspective. Nutrients, v.7, n.10, p.855, 2018. DOI: http://doi.org/10.3390/nu10070855

FERREIRA, R. L. S.; SILVA, D. T.; ARAÚJO, P. G.; HAMOY, I.;
MATOS, E.; VIDEIRA, M. N.. Henneguya sacacaensis n.sp. (Myxozoa: Myxosporea) parasitizing gills of the acará bicudo Satanoperca jurupari (Osteichthyes: Cichlidae) in eastern Amazon. Brazilian Journal of Veterinary Parasitology, v.29, n.2, p.e000620, 2020. DOI: http://doi.org/10.1590/s1984$\underline{29612020030}$

FLORINDO, M. C.. Diversidade de parasitos de peixes ornamentais dulcícolas cultivados em Santa Catarina. Dissertação (Mestrado em Aquicultura) - Universidade Federal de Santa Catarina, Florianópolis, 2016.

FROESE, R.; PAULY, D.. Fish Base. Worldwide web electronic publication, 2014.

GASCHLER, M. M.; STOCKWELL, B. R.. Lipid peroxidation in cell death. Biochemical and Biophysical Research Communications, v.482, n.3, p.419-425, 2017. DOI: http://doi.org/10.1016/j.bbrc.2016.10.086

GUTTERIDGE, J. M. C.; HALLIWELL, B.. Mini-Review: Oxidative stress, redox stress or redox success?. Biochemical 
and Biophysical Research Communications, v.502, n.2,

p.183-186, 2018. DOI:

http://doi.org/10.1016/i.bbrc.2018.05.045

JOARDAR, N.; BABU, S. P. S.. A review on the druggability of a thiol-based enzymatic antioxidant thioredoxin reductase for treating filariasis and other parasitic infections. International Journal of Biological Macromolecules, v.142, p.125-141, 2020. DOI: http://doi.org/10.1016/i.ijbiomac.2019.09.083

KHO, H. P.; LEOW, C. Y.; SHUEB, R. H.; LEOW, C. H.; LIM, B. $\mathrm{H}$.; $\mathrm{CHUAH}, \mathrm{C}$.. A hypothetical oxidative stress regulatory role of alpha giardins in the protozoan parasite Giardia intestinalis. Tropical Biomedicine, v.35, n.1, 41-49, 2018.

KULLANDER, S. O.. Family. In: REIS, R. R.; KULLANDER, S. O.; FERRARIS, C. J.. Check list of the freshwater fishes of South and Central America. Porto Alegre: EDIPUCRS, 2003. p.729.

KAPTANER, B.; DOGAN, A.. Variations in the lipid peroxidation and antioxidant biomarkers in some tissues of anadromous cyprinid fish during migration. Cellular and Molecular Biology, Noisy-le-Grand, v.65, n.3, p.58-65, 2019. DOI: http://doi.org/10.14715/cmb/2019.65.3.8

LACAZE, É.; GENDRON, A. D.; MILLER, J. L.; COLSON, T. L. L.; SHERRY, J. P.; GIRAUDO, M.; HOUDE, M.. Cumulative effects of municipal effluent and parasite infection in yellow perch: a field study using high-throughput RNA-sequencing. Science of The Total Environment, v.665, p.797-809, 2019. DOI: http://doi.org/10.1016/j.scitotenv.2019.02.155

LOWRY, O. H.; ROSEBROUGH, N. J.; FARR, A. L.; RANDALL, R. J.. Protein measurement with the Folin phenol reagent. Journal of Biological Chemistry, v.193, n.1, p.265-275, 1951.

LUANGMONKONG, T.; SURIGUGA, S.; MUTSAERS, H. A.; GROOTHUIS, G. M.; OLINGA, P.; BOERSEMA, M.. Targeting oxidative stress for the treatment of liver fibrosis. Reviews of Physiology, Biochemistry and Pharmacology, Springer, v.175, p.71-102, 2018. DOI: http://doi.org/10.1007/112 201810

LUNA, L. G.. Manual of histologic staining methods of the armed forces institute of pathology. New York: McGrawHill, 1968.

MEDA, S.; SINGH, S.; PALADE, P.; TONK, S.; AWASTHI, S.. Oxidative stress in intensive care unit patients: A review of glutathione linked metabolism and lipid peroxidation. The Southwest Respiratory and Critical Care Chronicles, v.7, n.27, p.7-35, 2019. DOI: http://doi.org/10.12746/swrccc.v7i27.511
MEHLHORN, H... Human parasites. Springer International Publishing, 2016. DOI: http://doi.org/10.1007/978-3-319$\underline{32802-7}$

NABI, S.; TANVEER, S.; GANIE, S. A.. Glutathione-Stransferase, superoxide dismutase (GST, SOD) levels, protein content and lipid peroxidation in Schizothorax plagiostomus under the infection of pomphorhynchus in nallah sukhnag of kashmir valley. Pakistan Journal of Biological Sciences, v.20, n.9, p.442-446, 2017. DOI:

http://dx.doi.org/10.3923/pjbs.2017.442.446

PAITAL, B.; GURU, D.; MOHAPATRA, P.; PANDA, B.; PARIDA, N.; RATH, S.; SRIVASTAVA, A.. Ecotoxic impact assessment of graphene oxide on lipid peroxidation at mitochondrial level and redox modulation in fresh water fish Anabas testudineus. Chemosphere, v.224, p.796-804, 2019. DOI: http://doi.org/10.1016/j.chemosphere.2019.02.156

RAHAL, A.; AMIT K.; VIVEK, S.; BRIJESH, Y.; RUCHI, T.; SANDIP, C.; KULDEEP, D.. Oxidative stress, prooxidants, and antioxidants: the interplay. BioMed Research International, v.2014, 2014. DOI: http://doi.org/10.1155/2014/761264

SORCI, G.; FAIVRE, B.. Inflammation and oxidative stress in vertebrate host-parasite systems. Philosophical Transactions of the Royal Society B: Biological Sciences, v.364, n.1513, p.71-83, 2009. DOI: http://doi.org/10.1098/rstb.2008.0151

SRIVASTAVA, B.; REDDY, P. B.. Lipid peroxidation and DNA damage as biomarkers of pollution induced oxidative stress (OS) in fish. International Journal Life Sciences, v.4, n.1, p.194-198, 2017. DOI: http://10.13140/RG.2.2.13114.80323

TAVARES-DIAS, M.; OLIVEIRA, M. S. B.; GONCALVES, R. A.; NEVES, L. R.. Parasitic diversity of a wild Satanoperca jurupari population, an ornamental cichlid in the Brazilian Amazon. Acta Amazônica, v.47, n.2, p.155-162, 2017. DOI: http://doi.org/10.1590/1809-4392201602514

TURRENS, J. F.. Oxidative stress and antioxidant defenses: a target for the treatment of diseases caused by parasitic protozoa. Molecular Aspects of Medicine, v.25, n.1-2, p.211-220, 2004. DOI: http://doi.org/10.1016/j.mam.2004.02.021

YEANG, H. Y.; YUSOF, F.; ABDULLAH, L.. Protein purification for the Lowry assay: acid precipitation of proteins in the presence of sodium dodecyl sulfate and other biological detergents. Analytical. Biochemistry, v.265, v.2, p.381-384, 1998. DOI: http://doi.org/10.1006/abio.1998.2893

A CBPC - Companhia Brasileira de Produção Científica (CNPJ: 11.221.422/0001-03) detém os direitos materiais desta publicação. Os direitos referem-se à publicação do trabalho em qualquer parte do mundo, incluindo os direitos às renovações, expansões e disseminações da contribuição, bem como outros direitos subsidiários. Todos os trabalhos publicados eletronicamente poderão posteriormente ser publicados em coletâneas impressas sob coordenação da Sustenere Publishing, da Companhia Brasileira de Produção Científica e seus parceiros autorizados. Os (as) autores (as) preservam os direitos autorais, mas não têm permissão para a publicação da contribuição em outro meio, impresso ou digital, em português ou em tradução. 